\title{
Restless legs syndrome in children with allergic rhinitis: A comparative study on frequency, severity and sleep quality
}

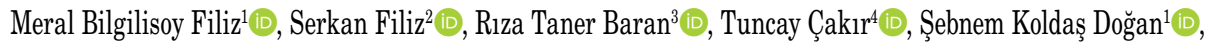 \\ Mesut Parlak ${ }^{5}$ (D), Naciye Füsun Toraman ${ }^{1}$ (D) \\ 'Department of Physical Medicine and Rehabilitation, Health Sciences University, Antalya Training and Research Hospital, Antalya, Turkey \\ ${ }^{2}$ Department of Pediatric Allergy and Immunology, Health Sciences University, Antalya Training and Research Hospital, Antalya, Turkey \\ ${ }^{3}$ Department of Department of Pediatric Endocrinology, Health Sciences University, Antalya Training and Research Hospital, Antalya, Turkey \\ ${ }_{4}^{4}$ Department of Physical Medicine and Rehabilitation, Private Likya Hospital, Antalya, Turkey \\ ${ }^{5}$ Department of Department of Pediatric Endocrinology, Medicine Faculty of Akdeniz University, Antalya, Turkey
}

Received: December 20, 2017 Accepted: January 11, 2018 Published online: March 12, 2018

\begin{abstract}
Objectives: This study aims to investigate the frequency and severity of restless legs syndrome (RLS) and its relationship with sleep quality in children with allergic rhinitis (AR) with the hypothesis that comorbid RLS may be an additional causative factor of sleep disturbances in pediatric AR.

Patients and methods: A total of 143 children with AR (aged 8-18 years) and 144 healthy control subjects (aged 8-18 years) were included. The diagnosis of AR was established on history, clinical examination and skin prick test according to the Allergic Rhinitis and its Impact on Asthma guidelines. Presence of RLS was determined using the International RLS study group (IRLSSG) criteria. The severity of RLS was assessed using the IRLSSG rating scale. Sleep quality was evaluated by Pittsburgh Sleep Quality Index (PSQI).

Results: Thirteen patients (9.1\%) in AR group, and six children (4.2\%) in control group had RLS (p=0.159). The frequency of RLS in AR group was higher than two folds when compared to the control group; however, the difference was not statistically significant. Restless legs syndrome severity score was significantly higher in AR group than control group (15.00 [11-20] and 11.00 [10-16] respectively, p=0.046). Total PSQI scores were similar between groups. Also, no significant differences were observed in total PSQI scores of AR patients with or without RLS.
\end{abstract}

Conclusion: Restless legs syndrome was not more common but was more severe in children with AR. There was no evidence that RLS has an obvious effect on sleep quality in children with AR.

Keywords: Allergic rhinitis; restless legs syndrome; sleep quality; Willis-Ekbom disease.

Allergic rhinitis (AR) is an inflammatory disease with symptoms including nasal congestion, rhinorrhea, sneezing, and pruritus of the eyes, nose and throat, and affects $20-40 \%$ of the general population in all over the world..$^{[1,2]}$ Approximately $80 \%$ of patients are symptomatic before the age of 20 and the overall prevalence of $\mathrm{AR}$ in childhood has been reported to be $40 \% \cdot{ }^{[2]}$ Allergic rhinitis has negative effects on sleep and professional life and causes poor quality of life..$^{[2,3]}$ Performance in daily life and work is affected by the disease in approximately $75-80 \%$ of the patients with AR in Europe and USA. ${ }^{[2-5]}$

Restless legs syndrome (RLS) is a chronic movement disorder, characterized by an urge to move legs usually accompanied by uncomfortable sensations and sleep disorders. The prevalence of the syndrome ranges from 1 to $15 \%$ in the general population, and about $2-4 \%$ of school-aged children and adolescents. ${ }^{[6,7]}$ The RLS symptoms which are worse at night and rest are partially or totally relieved by movements and may be

Corresponding author: Meral Bilgilisoy Filiz, MD. Sağllk Bilimleri Üniversitesi Antalya Ĕğitim ve Araştırma Hastanesi, Fiziksel Tip ve Rehabilitasyon Kliniği, 07100 Muratpaşa, Antalya, Turkey. e-mail: mbilgilisoy@gmail.com 
associated with sleep disturbances and psychosocial distress. ${ }^{[6,7]}$ Diagnosis is based on clinical features and the diagnostic criteria suggested by International RLS Study group (IRLSSG). ${ }^{[6]}$ However, RLS still remains underdiagnosed probably due to lack of accurate information about the disease. ${ }^{[8]}$

The etiology of pediatric RLS is poorly understood. The pathophysiology of RLS is focused on the dopaminergic system, reduced central nervous system iron and genetic linkages. ${ }^{[8-12]}$ Relationship between RLS and comorbid diseases such as iron deficiency, chronic renal failure and hyperactivity has been shown in pediatric age. ${ }^{[12-15]}$

Allergic rhinitis is found to be one of the most common reasons for sleep disorders in childhood. The disease itself or the drugs given for treatment may both result in fatigue and difficulty in concentration during day time. ${ }^{[16-18]}$ There is a strong relationship between poor sleep quality and AR with impaired nasal function. ${ }^{[2,16-18]}$ Also, the addition of RLS to AR may cause poor sleep quality or RLS and AR may have a potentiating effect on sleep.

To the best of our knowledge, there have been no studies to date that evaluate the relationship between RLS and AR in children, and the effects of RLS on sleep quality in pediatric AR patients. Therefore in this study, we aimed to investigate the frequency and severity of RLS and its relationship with sleep quality in children with AR with the hypothesis that comorbid RLS may be an additional causative factor of sleep disturbances in pediatric AR.

\section{PATIENTS AND METHODS}

\section{Study design and study population}

This cross-sectional study was carried out in the Health Sciences University, Antalya Training and Research Hospital Pediatric Allergy and Physical Medicine and Rehabilitation Departments between January 2015 and December 2015. The study protocol was approved by the Health Sciences University, Antalya Training and Research Hospital Ethics Committee (approval number: 2014-246). A written informed consent was obtained from parents of all participants. The study was conducted in accordance with the principles of the Declaration of Helsinki. The diagnosis of AR was established on history, clinical examination, and skin prick test according to Allergic Rhinitis and its Impact on Asthma guidelines (2010 version). ${ }^{[19]}$ The patients with AR were classified as intermittent or persistent $\mathrm{AR}$ according to the duration of symptoms and severity using the same guideline ${ }^{[19]}$ All children with AR (aged 8-18 years), who applied consecutively to the outpatient clinics of Pediatric Allergy during the study period were evaluated. Patients with an underlying disease such as anemia, uremia, cancer, peripheral vascular disease, collagen tissue disease, endocrinopathy (hyper/hypothyroidism, diabetes mellitus), polyneuropathy or myelopathy were excluded. Patients using neuroleptic and antiepileptic drugs were also excluded. Ultimately, 143 children with AR were enrolled in the study and 144 age matched, healthy control subjects (aged 8-18 years) without allergy and chronic illnesses were recruited as controls.

\section{Assessment parameters}

Restless legs syndrome assessment: All participants were evaluated by a face-to-face interview to determine the presence of RLS according to the revised IRLSSG criteria. ${ }^{[6]}$ Subjects who fulfilled all five criteria were diagnosed as RLS. Updated integrated RLS diagnostic criteria were listed in Table 1.

Restless legs syndrome symptom severity assessment: To evaluate the symptom severity, IRLSSG rating scale was applied to the patients diagnosed to have RLS. This scale consists of ten questions regarding typical symptoms of the disease. Each question is rated between 0 and 4 points. Higher global score indicates more severe disease. ${ }^{[20]}$

Skin prick test: A total of 18 allergen solutions, including the negative and positive controls, were employed. Saline and histamine were used as negative and positive controls, respectively. Allergens and

Table 1. International restless legs syndrome study group consensus diagnostic criteria for restless legs syndrome

1. An urge to move the legs usually but not always accompanied by, or felt to be caused by, uncomfortable and unpleasant sensations in the legs

2. The urge to move the legs and any accompanying unpleasant sensations begin or worsen during periods of rest or inactivity such as lying down or sitting

3. The urge to move the legs and any accompanying unpleasant sensations are partially or totally relieved by movement, such as walking or stretching, at least as long as the activity continues

4. The urge to move the legs and any accompanying unpleasant sensations during rest or inactivity only occur or are worse in the evening or night than during the day

5. The occurrence of the above features is not solely accounted for as symptoms primary to another medical or a behavioral condition (e.g. myalgia, venous stasis, leg edema, arthritis, leg cramps, positional discomfort, habitual foot tapping) 
Table 2. Demographic and clinical characteristics of allergic rhinitis patients and controls

\begin{tabular}{|c|c|c|c|c|c|c|c|c|c|}
\hline & \multicolumn{4}{|c|}{ Allergic rhinitis patients $(\mathrm{n}=143)$} & \multicolumn{4}{|c|}{ Controls $(n=144)$} & \multirow[b]{2}{*}{$p$} \\
\hline & $\mathrm{n}$ & $\%$ & Median & Min-Max & $\mathrm{n}$ & $\%$ & Median & Min-Max & \\
\hline Age (year) & & & 13 & $7-17$ & & & 13 & $7-17$ & $0.263^{\star}$ \\
\hline Gender & & & & & & & & & $0.236 \dagger$ \\
\hline Female & 71 & 49.7 & & & 81 & 56.2 & & & \\
\hline Male & 72 & 50.3 & & & 63 & 43.8 & & & \\
\hline Hemoglobin (g/dL) & & & 13.15 & $10.10-17.10$ & & & 13.30 & $9.60-16.10$ & $0.058^{*}$ \\
\hline Iron $(\mu \mathrm{g} / \mathrm{dL})$ & & & 73.00 & $10.00-361.00$ & & & 63.00 & $15.00-194.00$ & $0.135^{\star}$ \\
\hline Total iron binding capacity $(\mu \mathrm{g} / \mathrm{mL})$ & & & 382.00 & $24.00-547.00$ & & & 387.00 & $277.00-522.00$ & $0.097^{\star}$ \\
\hline Ferritine $(\mathrm{ng} / \mathrm{mL})$ & & & 20.00 & $2.00-361.00$ & & & 20.00 & $2.00-244.00$ & $0.385^{\star}$ \\
\hline Thyroid stimulation hormone $(\mu \mathrm{IU} / \mathrm{mL})$ & & & 1.99 & $0.60-17.90$ & & & 2.20 & $0.15-6.99$ & $0.020^{\star}$ \\
\hline Vitamin B12 (pg/mL) & & & 208.00 & $9.62-1500.00$ & & & 204.00 & $29.00-774.00$ & $0.913^{*}$ \\
\hline Folic acid $(\mathrm{ng} / \mathrm{mL})$ & & & 8.88 & $4.30-149.00$ & & & 9.31 & $1.42-112.86$ & $0.993^{*}$ \\
\hline Vitamin D (ng/mL) & & & 15.55 & $4.00-42.60$ & & & 12.80 & $4.62-38.80$ & $0.004^{*}$ \\
\hline Presence of RLS & 13 & 9.1 & & & 6 & 4.2 & & & $0.159 \dagger$ \\
\hline The RLS severity score & & & 15.00 & $11.00-20.00$ & & & 11.00 & $10.00-16.00$ & $0.046^{*}$ \\
\hline
\end{tabular}

Min: Minimum; Max: Maximum; RLS: Restless legs syndrome; ${ }^{\star}$ Mann-Whitney U test; $\dagger$ Chi-square test.

positive/negative controls were applied to the volar surface of arm epidermally with commercially available prick test solutions (Allergopharma $\mathrm{GmbH}$ \& CO KG, Reinbek, Germany). The allergens used included plants (trees, pine, verdure, grass, cereal, weed and olive), fungal spores (mixture of Alternaria, Cladosporium, Penicillium, Aspergillus), mites (Dermatophagoides pteronyssinus, Dermatophagoides farinae), and animal epithelium (cat, dog, bird). When positive control's edema was above $3 \mathrm{~mm}$ while there was no reaction in the negative control, the result was considered as positive in epidermal skin prick test.

Sleep quality: Sleep quality was assessed by Pittsburgh Sleep Quality Index (PSQI). PSQI is a questionnaire assessing sleep quality as well as presence and severity of a sleep disorder. It includes seven components and 19 self-rated questions assessing subjective sleep quality, sleep latency, sleep duration, habitual sleep efficiency, sleep disturbances, use of sleep medications and daytime dysfunction. All questions are rated between 0 and 3 points: 0 , not during past month; 1 , less than once a week; 2 , once or twice a week; 3 , three or more times a week. In addition, sleep quality is rated as follows: 0 , very good; 1 , fairly good; 2 , fairly bad, 3 very bad. Component scores are summed to obtain a global score ranging between 0-21 points. Higher global scores indicate worse sleep quality. Its diagnostic sensitivity and specificity are $89.6 \%$ and $86.5 \%$, respectively. ${ }^{[21]}$ Turkish validation and reliability study was performed by Agargun et al. ${ }^{[22]}$

Laboratory: As impaired iron homeostasis plays an important role in the pathogenesis of RLS, all patients were tested for iron deficiency. A complete iron panel, including serum hemoglobin, iron levels, ferritin, and total iron binding capacity were obtained. Also, thyroid-stimulating hormone, folic acid, vitamin B12 and vitamin D levels were analyzed.

\section{Statistical analysis}

Statistical analysis was performed using IBM SPSS version 20.0 software (IBM Corp., Armonk, NY, USA). Continuous variables were defined as median and range (minimum-maximum) with interquartile ranges for nonparametric tests. Although only nonparametric tests were used, mean \pm standard deviation values were given as well when necessary. Chi-square test was used for comparison of categorical variables. In the analysis of the difference between the values of the two groups, the normality hypothesis was tested with the Kolmogorov-Smirnov test, and as none of the parameters showed normal distribution, the Mann-Whitney $\mathrm{U}$ test was used. A $p$ value $<0.05$ was considered as statistically significant.

A power analysis by Minitab 17 Statistical Software (Minitab, Ltd., Coventry, United Kingdom) according to the results of Tuna et al. ${ }^{[23]}$ revealed that 117 patients would be required in each group to detect significant differences with a power of $90 \%$ and a level of significance of $\alpha=0.05$.

\section{RESULTS}

There were no significant differences between AR patients and controls in terms of age or gender. Demographic and clinical characteristics of $A R$ patients and controls were summarized in Table 2 . 
Table 3. Relationship of allergic rhinitis type and restless legs syndrome

\begin{tabular}{|c|c|c|c|c|c|}
\hline & \multicolumn{2}{|c|}{ Restless legs syndrome $(+)(n=13)$} & \multicolumn{2}{|c|}{ Restless legs syndrome (-) (n=130) } & \multirow[b]{2}{*}{$p^{*}$} \\
\hline & $\mathrm{n}$ & $\%$ & $\mathrm{n}$ & $\%$ & \\
\hline Intermittent allergic rhinitis $(\mathrm{n}=77)$ & 5 & 6.5 & 72 & 93.5 & \multirow{2}{*}{0.261} \\
\hline Persistent allergic rhinitis $(\mathrm{n}=66)$ & 8 & 12.1 & 58 & 87.9 & \\
\hline
\end{tabular}

${ }^{*}$ Chi-Square test.

Table 4. Relationship of sensitivity severity and restless legs syndrome

\begin{tabular}{|c|c|c|c|c|c|}
\hline \multirow[b]{2}{*}{ Number of sensitized allergens } & \multicolumn{2}{|c|}{ Restless legs syndrome $(+)(\mathrm{n}=12)$} & \multicolumn{2}{|c|}{ Restless legs syndrome (-) $(\mathrm{n}=130)$} & \multirow[b]{2}{*}{$p^{*}$} \\
\hline & $\mathrm{n}$ & $\%$ & $\mathrm{n}$ & $\%$ & \\
\hline $0-5 \quad(n=122)$ & 8 & 5.6 & 114 & 93.4 & 0.068 \\
\hline $6-10(n=20)$ & 4 & 20 & 16 & 80 & 0.068 \\
\hline
\end{tabular}

Restless legs syndrome: Thirteen patients (9.1\%) in AR group and six children (4.2\%) in control group had RLS ( $p=0.159)$. The frequency of RLS in AR group was more than two folds when compared to the control group; however, the difference was not statistically significant (Table 2).

Restless legs syndrome symptom severity: Restless legs syndrome severity score was significantly higher in AR group than control group (15.00 [11-20] and 11.00 [10-16] respectively, $\mathrm{p}=0.046$ ) (Table 2).

In AR group, 77 patients (53.8\%) had intermittent, and 66 patients (46.2\%) had persistent AR. Restless legs syndrome was two folds more frequent in persistent AR than intermittent form (12.1\% vs. $6.5 \%)$, but the difference was not statistically significant $(\mathrm{p}=0.261)$ (Table 3).

Skin prick test: Patients were stratified according to the number of allergens they were sensitive to. One of the groups was composed of patients who had sensitivity to $0-5$ allergens, and the other was composed of patients who had sensitivity to 6-10 allergens. Of the patients, 122 (85\%) had sensitivity to $0-5$ and $20(15 \%)$ to $6-10$ allergens. One patient refused to have a pinprick test. The frequency of RLS was $5.6 \%$ and $20 \%$ in the less sensitive group and more sensitive group, respectively $(\mathrm{p}=0.068)$ (Table 4$)$.

Sleep quality: There were no significant differences between AR patients and controls in terms of total PSQI scores $(p=0.730)$. In the subgroups of PSQI regarding sleep latency and sleep disturbances, $A R$ group had significantly worse scores $(p=0.002$ and $\mathrm{p}=0.001$, respectively). In habitual sleep efficiency and use of sleep medications subgroups, control group had significantly worse scores than AR group $(\mathrm{p}=0.022$ and $\mathrm{p}=0.002$, respectively). No differences were observed between two groups in subjective sleep quality, sleep duration or daytime dysfunction $(\mathrm{p}=0.913, \mathrm{p}=0.093$, and $\mathrm{p}=0.155$, respectively) (Table 5).

No significant difference was observed in total PSQI scores of AR patients with or without RLS $(\mathrm{p}=0.538)$. Only sleep disturbances subgroup score was significantly worse in RLS (+) group than RLS (-) group ( $\mathrm{p}=0.005$ ) (Table 6).

Persistent AR patients had slightly higher PSQI total and subgroup scores than intermittent AR patients, but this was not at a statistically significant level (Table 7).

Table 5. Mean and median Pittsburgh Sleep Quality Index scores of allergic rhinitis patients and controls

\begin{tabular}{lcccccccc}
\hline & \multicolumn{3}{c}{ Allergic rhinitis patients $(\mathrm{n}=143)$} & & \multicolumn{3}{c}{ Controls $(\mathrm{n}=144)$} \\
\cline { 2 - 4 } \cline { 6 - 7 } PSQI scores & Mean \pm SD & Median & Min-Max & & Mean \pm SD & Median & Min-Max & $p^{*}$ \\
\hline Subjective sleep quality & $0.7 \pm 0.6$ & 1.00 & $0.00-3.00$ & & $0.8 \pm 0.7$ & 1.00 & $0.00-3.00$ & 0.913 \\
Sleep latency & $1.0 \pm 0.7$ & 1.00 & $0.00-3.00$ & & $0.7 \pm 0.7$ & 1.00 & $0.00-3.00$ & 0.002 \\
Sleep duration & $0.3 \pm 0.5$ & 0.00 & $0.00-2.00$ & & $0.4 \pm 0.6$ & 0.00 & $0.00-2.00$ & 0.093 \\
Habitual sleep efficiency & $0.2 \pm 0.4$ & 0.00 & $0.00-1.00$ & & $0.3 \pm 0.4$ & 0.00 & $0.00-1.00$ & 0.022 \\
Sleep disturbances & $1.0 \pm 0.3$ & 0.00 & $0.00-2.00$ & & $0.8 \pm 0.4$ & 0.00 & $0.00-2.00$ & 0.001 \\
Use of sleep medications & $0.0 \pm 0.2$ & 0.00 & $0.00-1.00$ & & $0.1 \pm 0.4$ & 0.00 & $0.00-2.00$ & 0.002 \\
Daytime dysfunction & $1.5 \pm 1.6$ & 1.00 & $0.00-6.00$ & & $1.9 \pm 2.1$ & 2.00 & $0.00-6.00$ & 0.155 \\
Total PSQI score & $4.8 \pm 2.9$ & 4.00 & $1.00-11.00$ & & $4.5 \pm 2.4$ & 4.00 & $0.00-12.00$ & 0.00 \\
\hline
\end{tabular}

PSQI: Pittsburgh Sleep Quality Index; SD: Standard deviation; Min: Minimum; Max: Maximum; ${ }^{*}$ Mann-Whitney U test. 
Table 6. Mean and median Pittsburgh Sleep Quality Index scores of restless legs syndrome (+) or (-) patients in allergic rhinitis and persistent and intermittent allergic rhinitis

\begin{tabular}{|c|c|c|c|c|c|c|c|}
\hline \multirow[b]{2}{*}{ PSQI scores } & \multicolumn{3}{|c|}{ Restless legs syndrome (+) (n=13) } & \multicolumn{3}{|c|}{ Restless legs syndrome $(-) \quad(n=130)$} & \multirow[b]{2}{*}{$p^{*}$} \\
\hline & Mean \pm SD & Median & Min-Max & Mean \pm SD & Median & Min-Max & \\
\hline Subjective sleep quality & $0.9 \pm 0.9$ & 1.00 & $0.00-2.00$ & $0.7 \pm 0.6$ & 1.00 & $0.00-2.00$ & 0.375 \\
\hline Sleep latency & $1.3 \pm 0.5$ & 1.00 & $1.00-2.00$ & $0.9 \pm 0.7$ & 1.00 & $0.00-3.00$ & 0.115 \\
\hline Sleep duration & $0.1 \pm 0.3$ & 0.00 & $0.00-1.00$ & $0.3 \pm 0.5$ & 0.00 & $0.00-2.00$ & 0.116 \\
\hline Habitual sleep efficiency & $0.2 \pm 0.4$ & 0.00 & $0.00-1.00$ & $0.2 \pm 0.4$ & 0.00 & $0.00-1.00$ & 0.943 \\
\hline Sleep disturbances & $1.2 \pm 0.4$ & 1.00 & $1.00-2.00$ & $1.0 \pm 0.3$ & 1.00 & $0.00-2.00$ & 0.005 \\
\hline Use of sleep medications & NA & 0.00 & $0.00-0.00$ & $0.0 \pm 127$ & 0.00 & $0.00-1.00$ & 0.578 \\
\hline Daytime dysfunction & $1.3 \pm 1.5$ & 1.00 & $0.00-4.00$ & $1.5 \pm 1.6$ & 1.00 & $0.00-6.00$ & 0.880 \\
\hline Total PSQI score & $5.0 \pm 2.6$ & 4.00 & $3.00-10.00$ & $4.5 \pm 2.5$ & 4.00 & $0.00-11.00$ & 0.538 \\
\hline
\end{tabular}

PSQI: Pittsburgh Sleep Quality Index; SD: Standard deviation; Min: Minimum; Max: Maximum; ${ }^{*}$ Mann-Whitney U test.

Table 7. Mean and median Pittsburgh Sleep Quality Index scores of persistent and intermittent allergic rhinitis

\begin{tabular}{|c|c|c|c|c|c|c|c|}
\hline \multirow[b]{2}{*}{ PSQI scores } & \multicolumn{3}{|c|}{ Persistent AR $(n=66)$} & \multicolumn{3}{|c|}{ Intermittent $\mathrm{AR}(\mathrm{n}=77)$} & \multirow[b]{2}{*}{$p^{*}$} \\
\hline & Mean \pm SD & Median & Min-Max & Mean \pm SD & Median & Min-Max & \\
\hline Subjective sleep quality & $0.8 \pm 0.7$ & 1.00 & $0.00-2.00$ & $0.6 \pm 0.6$ & 1.00 & $0.00-3.00$ & 0.182 \\
\hline Sleep latency & $1.0 \pm 0.8$ & 1.00 & $0.00-3.00$ & $0.8 \pm 0.7$ & 1.00 & $0.00-3.00$ & 0.977 \\
\hline Sleep duration & $0.2 \pm 0.5$ & 0.00 & $0.00-2.00$ & $0.3 \pm 0.5$ & 0.00 & $0.00-2.00$ & 0.278 \\
\hline Habitual sleep efficiency & $0.2 \pm 0.3$ & 0.00 & $0.00-1.00$ & $0.2 \pm 0.4$ & 0.00 & $0.00-1.00$ & 0.462 \\
\hline Sleep disturbances & $1.1 \pm 0.3$ & 1.00 & $0.00-2.00$ & $1.0 \pm 0.3$ & 1.00 & $0.00-2.00$ & 0.160 \\
\hline Use of sleep medications & $0.01 \pm 0.1$ & 0.00 & $0.00-1.00$ & $0.01 \pm 0.2$ & 0.00 & $0.00-1.00$ & 0.391 \\
\hline Daytime dysfunction & $1.6 \pm 1.7$ & 1.00 & $0.00-6.00$ & $1.3 \pm 1.5$ & 1.00 & $0.00-5.00$ & 0.248 \\
\hline Total PSQI score & $4.8 \pm 2.7$ & 4.00 & $1.00-11.00$ & $4.4 \pm 2.4$ & 4.00 & $0.00-10.00$ & 0.554 \\
\hline
\end{tabular}

AR: Allergic rhinitis; PSQI: Pittsburgh Sleep Quality Index; SD: Standard deviation; Min: Minimum; Max: Maximum; ${ }^{\star}$ Mann-Whitney U test.

Laboratory: Mean hemoglobin, iron, total iron binding capacity, ferritin, vitamin B12 and folic acid levels were normal or similar between $\mathrm{AR}$ and control groups $(\mathrm{p}=0.058, \mathrm{p}=0.135, \mathrm{p}=0.097, \mathrm{p}=0.385, \mathrm{p}=0.913$, and $\mathrm{p}=0.993$, respectively). Significant differences were observed in thyroid stimulation hormone (TSH) and vitamin D levels between groups. In both groups, vitamin D levels were under normal limits; however, in AR group, it was significantly higher than the control group $(\mathrm{p}=0.004)$. TSH levels were normal in both groups and significantly lower in AR group $(\mathrm{p}=0.020)$ (Table 2).

\section{DISCUSSION}

To the best of our knowledge, this is the first study that assessed the frequency of RLS in children with AR and its impact on sleep quality. Restless legs syndrome was two-fold more frequent in AR patients when compared to controls ( $9.1 \%$ vs. $4.2 \%$ ); however, this difference did not reach a statistically significant level. On the other hand, symptom severity of RLS was found to be significantly worse in patients with $\mathrm{AR}$, which gives the impression that AR mainly affects the severity of RLS, not the frequency. The ratio of RLS in control group was $4.2 \%$, which was similar to the previously reported ratios $(2-4 \%) \cdot{ }^{[24,25]}$ There was no evidence that RLS has an obvious effect on sleep quality in children with AR.

Various studies showed the increased frequency of RLS and its association with poor sleep quality in many diseases such as chronic renal failure, ${ }^{[26]}$ fibromyalgia, ${ }^{[27]}$ ankylosing spondylitis, ${ }^{[28]}$ lumbar radiculopathy, ${ }^{[29]}$ inflammatory bowel disease, ${ }^{[30]}$ or primary biliary cirrhosis. ${ }^{[31]}$ However, there exist only a small number of studies which investigate the relationship between RLS and allergic diseases in adults, but not in children. In these studies, a possible correlation has been reported between the two diseases. ${ }^{[23,32]}$ In atopic dermatitis patients, RLS was found to be more frequent and correlated with the disease severity compared with psoriasis and control groups ${ }^{[32]}$ In another study, Tuna et al. ${ }^{[23]}$ showed that frequencies of RLS and sleep disturbances were higher in patients with chronic urticaria than the control group. Authors claimed that RLS and urticaria might share a common etiology and urticaria might trigger and worsen RLS. In the present study, RLS was more common in AR patients compared to control group, and in more sensitive AR patients compared to less sensitive ones; however, these differences were not 
statistically significant. In this study, most of the children in AR group had sensitivity to fewer allergens (122 children were sensitive to 0-5 allergens, while 20 children were sensitive to 6-10 allergens). In other words, children with AR in the study group mostly had a mild form of the disease. This may be a reason for the nonsignificant differences.

The association between AR and RLS may be due to several reasons. Although the pathophysiology of RLS still remains unclear, dopamine dysfunction, genetic factors and iron deficiency are thought to be the leading causes of RLS. ${ }^{[9-12,33]}$ Also, recent studies suggest possible roles for inflammatory and/or immune mechanisms in the pathogenesis of RLS. ${ }^{[27,29,33]}$ Weinstock et al. ${ }^{[33]}$ reviewed the diseases and conditions associated with RLS and found that 42 of the 47 (89\%) RLS-associated conditions were related with inflammatory and/or immune changes. Imbalances in innate and adaptive immunity together with environmental factors are likely to play major roles in AR. ${ }^{[34]}$ Inflammation and altered immunity in AR may contribute to iron deficiency and hypothetically cause central nervous system iron deficiency-induced RLS. Furthermore, antihistamines that are commonly used for the treatment of AR block dopamine receptors. ${ }^{[6,7,31]}$ Dopaminergic dysfunction caused by antihistamines may be a reason for increased severity of RLS symptoms.

Allergic rhinitis is a well-known and important risk factor for sleep disturbances. ${ }^{[2,16-18]}$ The reasons for poor sleep quality are not clearly defined, but nasal congestion and elevated inflammatory cytokines have been reported to be the likely causes of sleep impairment. ${ }^{[2,16]}$ Colás et al. ${ }^{[35]}$ reported that among 2,275 patients with AR, $52.8 \%$ had sleep disturbances and sleep quality was affected by severity of the disease. In the present study, sleep quality assessed by PSQI was similar in AR and control groups, and in contrast with our hypothesis, our results showed that presence of RLS did not seem to have any negative effect on sleep quality in AR.

This study has a number of limitations. The study group was composed of patients with sensitivity to fewer allergens; therefore, our results may not represent all patients with AR. Another limitation is that we did not perform polysomnography examination for the patients. The IRLSSG rating scale that was used to assess the severity of RLS had no Turkish validity and reliability study, which was another limitation of our study. However, in the literature, there are several manuscripts that have used IRLSSG rating scale in
Turkish population. ${ }^{[36,37]}$ Moreover, this scale was developed for adults, not for children. Nevertheless, due to the lack of a scale appropriate for children, it has been used in pediatric RLS studies as well. ${ }^{[38]}$ For all these reasons, despite its limitations, this scale was used in our study. Another limitation was PSQI having validation only for Turkish adults and not for Turkish children. Then again, as far as we know, there is no sleep quality index for which Turkish validity and reliability study has been conducted for children and this index has been used in several articles to assess sleep quality of Turkish children. ${ }^{[39,40]}$ Thus, PSQI was preferred in the current study.

In conclusion, our study showed that RLS may be more severe but is not associated with poor sleep quality in children with AR. Despite its high prevalence, RLS continues to be greatly underrecognized and undertreated in childhood. We advise clinicians to screen children with AR for comorbid diseases such as RLS to improve patients' quality of life. Additional studies are needed to confirm and expand upon our results.

\section{Declaration of conflicting interests}

The authors declared no conflicts of interest with respect to the authorship and/or publication of this article.

\section{Funding}

The authors received no financial support for the research and/or authorship of this article.

\section{REFERENCES}

1. Bauchau V, Durham SR. Prevalence and rate of diagnosis of allergic rhinitis in Europe. Eur Respir J 2004;24:758-64.

2. Thompson A, Sardana N, Craig TJ. Sleep impairment and daytime sleepiness in patients with allergic rhinitis: the role of congestion and inflammation. Ann Allergy Asthma Immunol 2013;111:446-51.

3. Bousquet J, Schunemann HJ, Samolinski B, Demoly P, Baena-Cagnani CE, Bachert C, et al. Allergic Rhinitis and its Impact on Asthma (ARIA): achievements in 10 years and future needs. J Allergy Clin Immunol 2012;130:1049-62.

4. Walker S, Khan-Wasti S, Fletcher M, Cullinan P, Harris J, Sheikh A. Seasonal allergic rhinitis is associated with a detrimental effect on examination performance in United Kingdom teenagers: case-control study. J Allergy Clin Immunol 2007;120:381-7.

5. Mir E, Panjabi C, Shah A. Impact of allergic rhinitis in school going children. Asia Pac Allergy 2012;2:93-100.

6. Allen RP, Picchietti DL, Garcia-Borreguero D, Ondo WG, Walters AS, Winkelman JW, et al. International Restless Legs Syndrome Study Group. Restless legs syndrome/WillisEkbom disease diagnostic criteria: updated International Restless Legs Syndrome Study Group (IRLSSG) consensus criteria--history, rationale, description, and significance. Sleep Med 2014;15:860-73. 
7. Silva GE, Goodwin JL, Vana KD, Vasquez MM, Wilcox PG, Quan SF. Restless legs syndrome, sleep, and quality of life among adolescents and young adults. J Clin Sleep Med 2014;10:779-86.

8. Allen RP. Restless Legs Syndrome/Willis-Ekbom disease pathophysiology. Sleep Med Clin 2015;10:2017-14.

9. Simakajornboon N, Kheirandish-Gozal L, Gozal D. Diagnosis and management of restless legs syndrome in children. Sleep Med Rev 2009;13:149-56.

10. Rangarajan S, D’Souza GA. Restless legs syndrome in Indian patients having iron deficiency anemia in a tertiary care hospital. Sleep Med 2007;9:88-93.

11. Araujo SM, de Bruin VM, Nepomuceno LA, Maximo ML, Daher Ede F, Correia Ferrer DP, et al. Restless legs syndrome in end-stage renal disease: clinical characteristics and associated comorbidities. Sleep Med 2010;11:785-90.

12. Halac G, Sezer GM, Saglam NO, Tekturk P, Demir $\mathrm{AD}$, Demir S, et al. The relationship between WillisEkbom disease and serum ferritin levels among children in Northwestern Turkey. Neurosciences (Riyadh) 2015;20:336-40.

13. Stabouli S, Papadimitriou E, Printza N, Dotis J, Papachristou F. Sleep disorders in pediatric chronic kidney disease patients. Pediatr Nephrol 2016;31:1221-9.

14. Hvolby A. Associations of sleep disturbance with ADHD: implications for treatment. Atten Defic Hyperact Disord 2015;7:1-18.

15. Pullen SJ, Wall CA, Angstman ER, Munitz GE, Kotagal S. Psychiatric comorbidity in children and adolescents with restless legs syndrome: a retrospective study. J Clin Sleep Med 2011;7:587-96.

16. Mullol J, Maurer M, Bousquet J. Sleep and allergic rhinitis. J Investig Allergol Clin Immunol 2008;18:415-19.

17. Santos CB, Pratt EL, Hanks C, McCann J, Craig TJ. Allergic rhinitis and its effect on sleep, fatigue and daytime somnolence. Ann Allergy Asthma Immunol 2006;97:579-89.

18. Sundberg R, Toren K, Hoglund D, Aberg N, Brisman J. Nasal symptoms are associated with school performance in adolescents. J Adolesc Health 2007;40:581-3.

19. Brozek JL, Bousquet J, Baena-Cagnani CE, Bonini S, Canonica GW, Casale TB, et al. Allergic Rhinitis and its Impact on Asthma (ARIA) guidelines: 2010 revision. J Allergy Clin Immunol 2010;126:466-76.

20. Walters AS, LeBrocq C, Dhar A, Hening W, Rosen R, Allen $\mathrm{RP}$, Trenkwalder C; International Restless Legs Syndrome Study Group Validation of the International Restless Legs Syndrome Study Group rating scale for restless legs syndrome. Sleep Med 2003;4:121-32.

21. Buysse DJ, Reynolds CF, Monk TH, Berman SR, Kupfer DJ. The Pittsburgh Sleep Quality Index: a new instrument for psychiatric practice and research. Psychiatry Res 1989;28:193-213.

22. Agargun MY, Kara H,Anlar Ö. Validity and reliability of the Pittsburg sleep quality index in Turkish sample. Turk J Psychiatry 1996;7:100-15.

23. Tuna S, Alan S, Samancı N, Karakaş AA. Is There an Association between Restless Legs Syndrome and Urticaria? J Korean Med Sci 2016;31:790-4.
24. Picchietti D, Allen RP, Walters AS, Davidson JE, Myers A, Ferini-Strambi L. Restless legs syndrome: prevalence and impact in children and adolescents--the Peds REST study. Pediatrics 2007;120:253-66.

25. Yilmaz K, Kilincaslan A, Aydin N, Kor D. Prevalence and correlates of restless legs syndrome in adolescents. Dev Med Child Neurol 2011;53:40-7.

26. Libório AB, Santos JP, Minete NF, de Diógenes CA, Farias Lde A, de Bruin VM. Restless legs syndrome and quality of sleep in patients with glomerulopathy. BMC Nephrol 2013;14:113.

27. Civelek GM, Ciftkaya PO, Karatas M. Evaluation of restless legs syndrome in fibromyalgia syndrome: an analysis of quality of sleep and life. J Back Musculoskelet Rehabil 2014;27:537-44.

28. Demirci S, Demirci K, Doğru A, İnal EE, Koyuncuoğlu HR, Şahin M. Restless legs syndrome is associated with poor sleep quality and quality of life in patients with ankylosing spondylitis: a questionnaire-based study. Acta Neurol Belg 2016;116:329-36.

29. Kocabicak E, Terzi M, Akpinar K, Paksoy K, Cebeci I, Iyigun O. Restless leg syndrome and sleep quality in lumbar radiculopathy patients. Behav Neurol 2014;2014:245358.

30. Schindlbeck KA, Becker J, Berger F, Mehl A, Rewitzer C, Geffe $S$, et al. Impact of restless legs syndrome in patients with inflammatory bowel disease on sleep, fatigue, and quality of life. Int J Colorectal Dis 2017;32:125-130.

31. Anderson K, Jones DE, Wilton K, Newton JL.Restless leg syndrome is a treatable cause of sleep disturbance and fatigue in primary biliary cirrhosis. Liver Int 2013;33:23943.

32. Cicek D, Halisdemir N, Dertioglu SB, Berilgen MS, Ozel S, Colak C. Increased frequency of restless legs syndrome in atopic dermatitis. Clin Exp Dermatol 2012;37:469-76.

33. Weinstock LB, Walters AS, Paueksakon P. Restless legs syndrome--theoretical roles of inflammatory and immune mechanisms. Sleep Med Rev 2012;16:341-54.

34. Eifan AO, Durham SR. Pathogenesis of rhinitis. Clin Exp Allergy 2016;46:1139-51.

35. Colás C, Galera H, Añibarro B, Soler R, Navarro A, Jáuregui I, et al. Disease severity impairs sleep quality in allergic rhinitis (The SOMNIAAR study). Clin Exp Allergy 2012;42:1080-7.

36. Yılmaz S, Çiğdem B, Gökçe ŞF, Ceyhan-Doğan S, Balaban $\mathrm{H}$. Severity and frequency of restless legs syndrome in patients with familial Mediterranean fever. J Int Med Res 2017;45:1340-6.

37. Kucuk A, Uslu AU, Yilmaz R, Salbas E, Solak Y, Tunc R. Relationship between prevalence and severity of restless legs syndrome and anemia in patients with systemic lupus erythematosus. Int J Rheum Dis 2017;20:469-73.

38. Gagliano A, Aricò I, Calarese T, Condurso R, Germanò E, Cedro C, et al. Restless Leg Syndrome in ADHD children: levetiracetam as a reasonable therapeutic option. Brain Dev 2011;33:480-6.

39. Üçer O, Gümüş B. Quantifying subjective assessment of sleep quality, quality of life and depressed mood in children with enuresis. World J Urol 2014;32:239-43.

40. Uyan ZS, Turan I, Ay P, Cakir E, Ozturk E, Gedik AH, et al. Sleep disordered breathing and sleep quality in children with bronchiolitis obliterans. Pediatr Pulmonol 2016;51:308-15. 